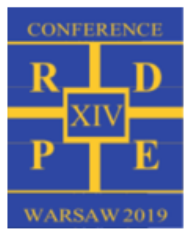

\title{
Analysis of a micro oxy gas turbine for variable oxidizer and fuel parameters
}

Wojciech Nowak ${ }^{1}$, Mikołaj Złotkowski ${ }^{1}$,

${ }^{1}$ A GH U niversity of Science and Technology, K rakow, wnowak@agh.edu.pl, Poland

A hmed A. A lharbi ${ }^{2}$

${ }^{2}$ K ing A bdul A ziz City for Science \& Technology - KACST, ahal harbi@ kacst.edu.sa, Saudi A rabia

\begin{abstract}
The article describes the behavior of a micro oxy gas turbine after replacing the nitrogen with carbon dioxide. The accurate simulation of the oxy turbine behavior is of great importance to understand its performance under a variety of operational parameters. This work presents combustion analysis for the comprehensive simulation of a micro oxy gas turbine.
\end{abstract}

\section{Introduction}

Carbon capture and storage (CCS) of $\mathrm{CO}_{2}$ from large energy sources can be the effective solution to decrease the global release of greenhouse gases. CCS has the possibility of storing the large amount of produced $\mathrm{CO}_{2}$ in geological formations.

Three main technology options of $\mathrm{CO}_{2}$ reduction are:

- $\quad$ separation $\mathrm{CO}_{2}$ after the combustion process (postcombustion capture),

- $\quad$ separation $\mathrm{CO}_{2}$ before the process (pre-combustion capture),

- combustion in oxygen atmosphere (oxy-fuel combustion) [1].

One cannot show on the present stage of the technology development, which among these technologies has the largest potential to reduce costs and energy needed to run the process of carbon capture and storage. Therefore, there is a need for intensive $R \& D$ since each of these technologies has the different approach to capture $\mathrm{CO}_{2}$. Although the CCS technology causes increasing fuel consumption because of the inevitable decrease of the process efficiency, the achievement of the significant reduction of greenhouse gases is until now a better solution than the potential which is possible through the increase of power efficiency.

The gas turbine allows the conversion of gas fuels into mechanical energy with efficiency of up to $25-45 \%$, it is a simple construction having as few as possible movable or friction elements, unlike the piston engine is a flow machine, it does not have connecting rods, oil sumps, valves or camshaft, which makes with the failure rate of individual elements may be lower. In order for the gas turbine to work properly, the fuel must be supplied in a gas form in the purest possible form. Fuel contamination negatively affects the lifetime of the turbine. It was assumed that fuel would be methane. This gives the chance that in the future it may be the only hydrocarbon fuel regarded as renewable and clean in combustion. In conventional air combustion, the capture of $\mathrm{CO}_{2}$ from flue gas is a complicated process due to the low partial pressure of $\mathrm{CO}_{2}$ and large amount of nitrogen in the flue gases. Since air contains $79 \%$ of nitrogen, all of nitrogen in different chemical forms is emitted to atmosphere during the combustion process, this the $\mathrm{CO}_{2}$ concentration in the flue gases is only in a range of 13$16 \%$ vol.

Oxy-fuel combustion is a process whereby oxygen is separated from the air and used directly to burn the fuel in order to increase the $\mathrm{CO}_{2}$ concentration in the flue gases to $90 \%$ vol., or greater. The volume of flue gases is significantly reduced by elimination of nitrogen and a $\mathrm{CO}_{2}$-enriched gas after removing water is ready for sequestration without $\mathrm{CO}_{2}$ capture. Oxy-combustion power production involves three major components: oxygen production (air separation unit ASU), the oxycombustion gas turbine (combustion unit), and $\mathrm{CO}_{2}$ purification and compression [2-5].

These components, along with different design options, are shown in Figure 1. 


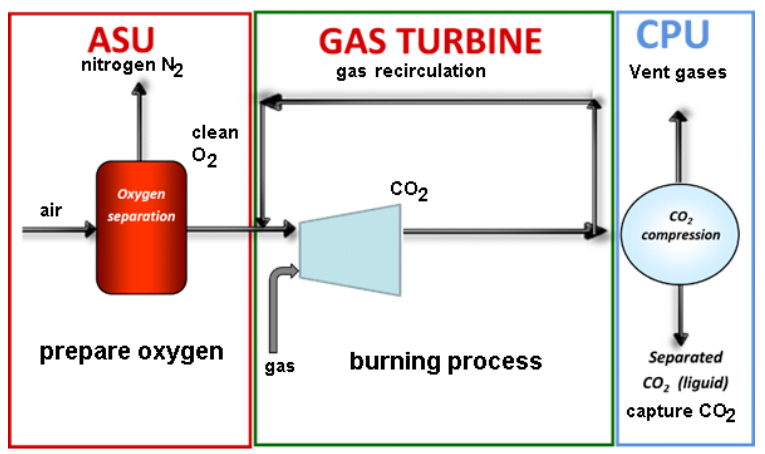

Fig. 1. Components of the oxy gas combustion unit.

Oxy-combustion gas turbine can be configured differently with these components, resulting in different energetic and economic performances. Systems can be configured in either low- or high-temperature designs. In low-temperature designs, flame temperatures are similar to that of air-fired combustion $\left(\sim 1600^{\circ} \mathrm{C}\right)$, while flame temperatures exceed $2500{ }^{\circ} \mathrm{C}$ in the advanced hightemperature design. Low-temperature designs for new or retrofit applications recycle combustion products to lower the flame temperature to approximate the heat transfer characteristics of air-fired turbines. Hightemperature designs use increased radiant heat transfer in new construction applications to reduce the size and capital cost of the gas turbine.

M icro Turbine Natural Gas C30 kW has been selected in the present studies. The parameters of the turbine are as follows:

$\begin{array}{ll}\text { Electric power output } & 30 \mathrm{~kW} \\ \text { Frequency } & 50 / 60 \mathrm{~Hz} \\ \text { Fuel } & 8-13 \mathrm{MJ} / \mathrm{m}^{3} \\ \text { Consumption fuel max } & 444 \mathrm{MJ} / \mathrm{h} \\ \text { Heat emission } & 14,4 \mathrm{MJ} / \mathrm{kWh} \\ \text { N Ox emission } & 18 \mathrm{mg} / \mathrm{m}^{3} \\ \text { NOx emission } & 0,23 \mathrm{~g} / \mathrm{hp}(\mathrm{h}) \\ \text { Exhaust gas flow } & 0,31 \mathrm{~kg} / \mathrm{s} \\ \text { Exhaust gas temperature } & 275^{\circ} \mathrm{C}\end{array}$

Gas power system achieves ultra-low emissions and reliable electricity from natural gas and the system can be transferred to oxy combustion after modifications. $M$ icroturbines use a lean premix combustion system to achieve low emissions levels at a full power range. $\mathrm{M}$ icroturbine control and power electronic systems allow for different operation modes, such as: grid connect, stand-alone, dual mode and multiple units for potentially enhanced reliability. M icro oxy turbine achieves almost zero $\mathrm{NO}_{x}$ emissions and reliable electricity from natural gas. In addition, oxy-gas combustion is emerging as an attractive option to facilitate capture and sequestration of $\mathrm{CO}_{2}$ from gas-fired power plants.

The accurate simulation of the oxy turbine behavior is of great importance to understand its performance under a variety of operational parameters. The paper discusses the oxy-fuel combustion development addressing the problem of oxy-fuel concept in a gas turbine. In particular, this work presents combustion analysis for the comprehensive simulation of a micro oxy gas turbine.

\section{Method}

Calculations of turbine operation parameters are carried out using the IPSEpro. It is a highly flexible environment for modelling, simulation, analysis and design of components and processes for energy and chemical engineering. Initial conditions of the turbine performance were taken from the documentation of the gas unit. Then the air atmosphere was changed to oxy one. Carbon dioxide, having a lower heat capacity, needs less fuel and oxygen to be supplied to the combustion chamber, resulting in similar turbine performance as with air. In case of oxy combustion mass share of exhaust gases is over $90 \% \mathrm{CO}_{2}, 8 \% \mathrm{O}_{2}$ and $2 \%$ methane.

Controlled $\mathrm{CO}_{2}$ recirculation allows to keep the temperature in the combustion chamber same as during air combustion. $\quad \mathrm{CO}_{2}$-rich flue gases with gas recirculation leaving the gas turbine contains $96 \% \mathrm{CO}_{2}$ and $4 \% \mathrm{H}_{2} \mathrm{O}$. A drying unit may be used, depending on requirements for the final $\mathrm{CO}_{2}$ stream applications. The $\mathrm{NOx}$ formation, when applying $\mathrm{O}_{2} / \mathrm{CO}_{2}$ recycle combustion, is expected to be very small since the nitrogen supplied by the air is removed, thus eliminating the thermal NOx formation. In case of air combustion, the exhaust gas contains only $14 \% \mathrm{CO}_{2}$ and $12 \% \mathrm{H}_{2} \mathrm{O}-$ the rest is nitrogen.

Figure 2 shows simulations of a gas turbine working on oxy atmosphere mode. Air is compressed in a 1:4 ratio and the use of heat exchangers between stages of compression, reduces energy demand. The water removes heat from the air from 28 to $55^{\circ} \mathrm{C}$, taking $1 \mathrm{~kW}$ of thermal power from the compressors. Air compressed to 4 bar is heated to $130^{\circ} \mathrm{C}$ and then mixed with methane to form a lean mixture, $\lambda=1.05$. Behind the combustion chamber, the temperature rises to $1600{ }^{\circ} \mathrm{C}$ and hot gases drive the turbine. Around $40 \%$ of the energy transferred to the turbine is used to drive the compressors, the rest is converted into electricity generating $23 \mathrm{~kW}$. The flue gases behind the turbine have high temperature and low pressure. The last exchanger absorbs this heat, converting water into superheated steam of $740{ }^{\circ} \mathrm{C}$ and 1.8 bar; the temperature of flue gases behind the exchanger is approx. in a range of $120-150^{\circ} \mathrm{C}$.

For oxy combustion compressing gas needs more power than oxygen and nitrogen. Temperature gases going to turbine are $950{ }^{\circ} \mathrm{C}$, the turbine generates $6 \mathrm{~kW}$ electric power, gas outlet turbine have $785{ }^{\circ} \mathrm{C}$; the entrophy lose on the turbine is only $220 \mathrm{~kJ} / \mathrm{kg}$. The water with cooling cycle heated to $60^{\circ} \mathrm{C}$ after two heat exchanger; after third cheat exchanger the temperature is $107^{\circ} \mathrm{C}$. It is near evaporation $(2000 \mathrm{~kJ} / \mathrm{kg})$. The exhaust gas after third heat exchanger have temperature less than $100^{\circ} \mathrm{C}$, the water can by condensing; its $\mathrm{pH}$ is about 7 and condensation is safety. 


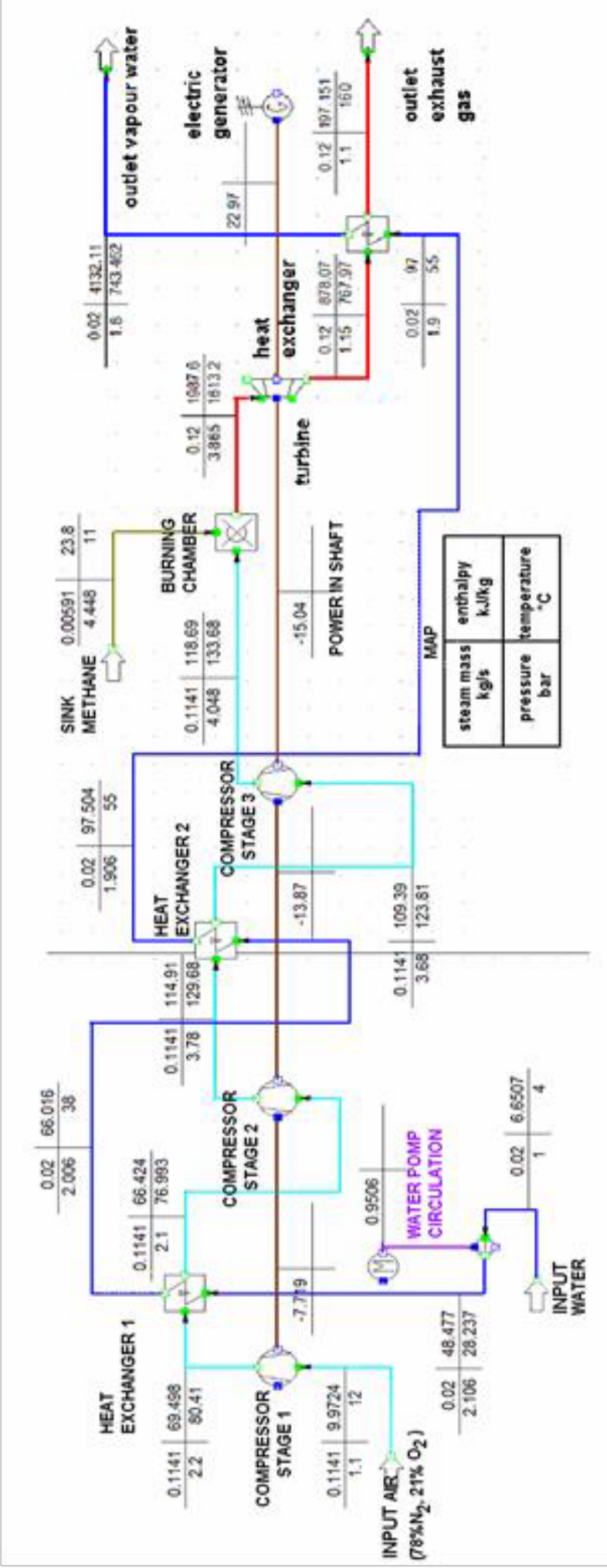

Fig. 2. Simulations in IPSEpro.

\section{Results}

Figure 3 shows the exhaust gas temperature at the turbine outlet as a function of the oxygen mass flow at a variable $\mathrm{CO}_{2}$ flow. For an oxygen flow of $8 \mathrm{~g} / \mathrm{s}$ the mixture is rich $(\lambda=0.18)$, so the temperature of the exhaust gas tends to increase. The higher the $\mathrm{CO}_{2}$ content, the temperature gradient is lower since the more heat can be absorbed by the higher the $\mathrm{CO}_{2}$ flow. The maximum temperature of $1120{ }^{\circ} \mathrm{C}$ for a of $24 \mathrm{~g} / \mathrm{s} \mathrm{O}_{2}$ flow was reached $(\lambda=1)$ at the lowest $\mathrm{CO}_{2}$ flow $(55 \mathrm{~g} / \mathrm{s})$.

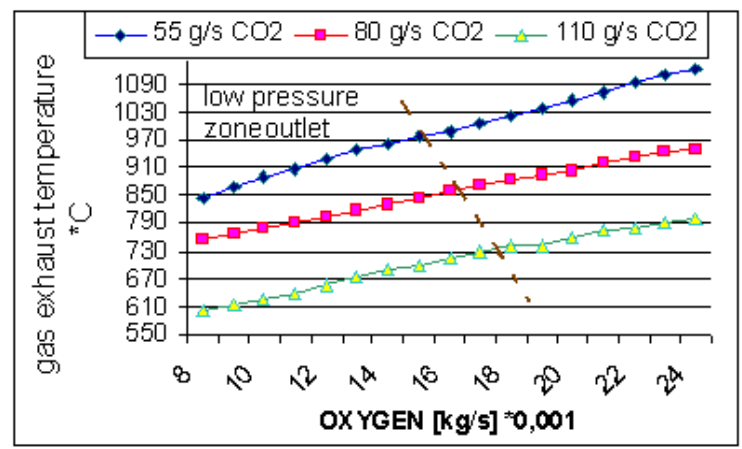

Fig. 3. Exhaust gas temperature at the turbine outlet as a function of the oxygen mass flow for different $\mathrm{CO} 2$ flows and $30 \mathrm{~kW}$ of power generation.

The higher the $\mathrm{CO}_{2}$ recycled flow, the less the temperature profile since the more heat can be absorbed by a higher gas flow. The maximum temperature of 770 ${ }^{\circ} \mathrm{C}$ was reached for the $9 \mathrm{~g} / \mathrm{s} \mathrm{O}_{2}$ when the mixture becomes lean.

Figure 4 shows the flue gas temperature as a function of $\mathrm{CO}_{2}$ mass flow. Four curves are shown for fuel mass composition 24:6 $(\lambda=1), 48: 6(\lambda=2), 72: 6(\lambda=3)$ and 96:6 $(\lambda=4) \mathrm{g} / \mathrm{s}$ and for the constant load of the generator $26 \mathrm{~kW}$. Hyperbolic course of temperature drop can be observed when the $\mathrm{CO}_{2}$ share increases. In this way, the combustion process is controlled so that the power generated by the turbine can be smoothly adjusted. The response to the change in the exhaust gas temperature is a quick correction of the $\mathrm{CO}_{2}$ flow at the entrance to the combustion chamber. Keeping the stoichiometric mixture (blue line), the temperature of the exhaust gases can be controlled over a wide range from 300 to $1150^{\circ} \mathrm{C}$. In order for the turbine to be able to generate $26 \mathrm{~kW}$ it is necessary to have an outlet pressure lower than atmospheric pressure. The turbine will not be able to generate $26 \mathrm{~kW}$ for $\mathrm{CO}_{2}$ flow larger than $140 \mathrm{~g} / \mathrm{s}$. 


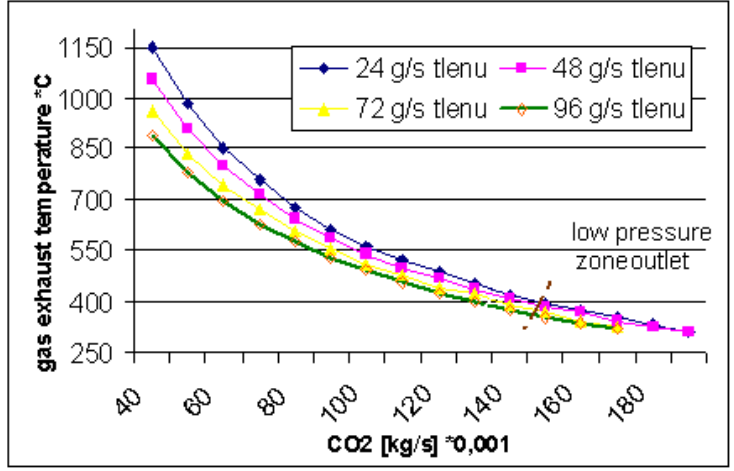

Fig. 4. The flue gas temperature as a function of $\mathrm{CO}_{2}$ mass flow.

Figure 5 presents a comparison of maximum temperatures for $40 \mathrm{~g} / \mathrm{s}$ of $\mathrm{CO}_{2}$ with different oxygen flows. As can be seen, raising the oxygen content above the stoichiometric ratio results in a decrease in the temperature measured at the turbine outlet.

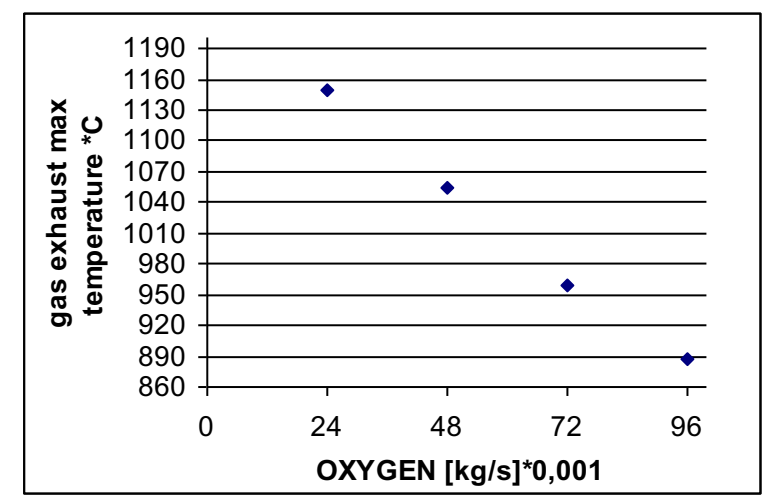

Fig.5. Comparison of average temperatures with the oxygen flow.

Figure 6 shows the exhaust gas temperature as a function of the fuel flow for different turbine loads of 2, 12 and $30 \mathrm{~kW}$, respectively.

By increasing the concentration of $\mathrm{CH}_{4}$ in the mixture, the power generated by the turbine increases. For a small fuel flow the turbine generates a low power of only 1 $\mathrm{kW}$ and then the power generated increases rapidly. It is possible to generate even $12 \mathrm{~kW}$ for a fuel flow of $2 \mathrm{~g} / \mathrm{s}$. If $\lambda$ is less than 1.4 the temperature increase and it is possible to generate $30 \mathrm{~kW}$ of power. For stoichiometric mixtures, the temperature of the exhaust gases reaches $1150{ }^{\circ} \mathrm{C}$. When the mixture becomes rich, the temperature increase is no longer significant and for $\lambda=$ 0.8 reaches $1200{ }^{\circ} \mathrm{C}\left(\mathrm{CO}_{2} /\right.$ oxygen ratio is $\left.70: 18\right)$.

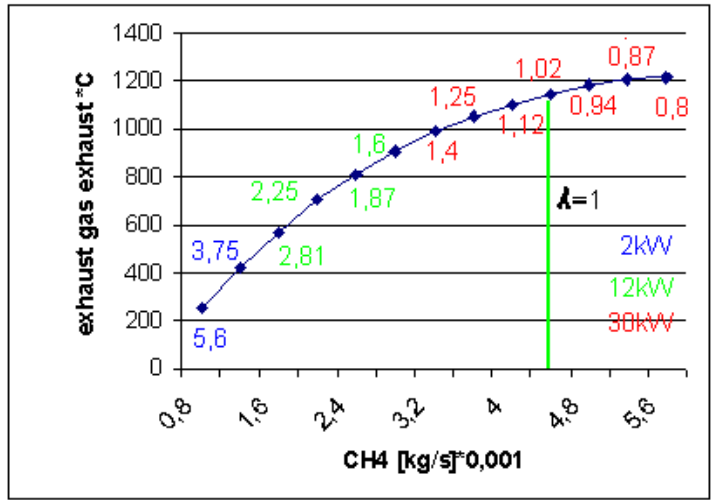

Fig. 6. The exhaust gas temperature as a function of the fuel flow.

Figure 7 shows the gas exhaust temperature as a function of the fuel flow for the turbine loads of 1 and $10 \mathrm{~kW}$, and constant the $\mathrm{CO}_{2}$ mass flow.

By increasing the oxygen concentration in the mixture, the power generated by the turbine increases; for low fuel content the turbine generates less power, but by increasing the fuel content the power increases rapidly to a level of $10 \mathrm{~kW}$. The temperature reaches $700{ }^{\circ} \mathrm{C}$ and stabilizes for richer mixtures.

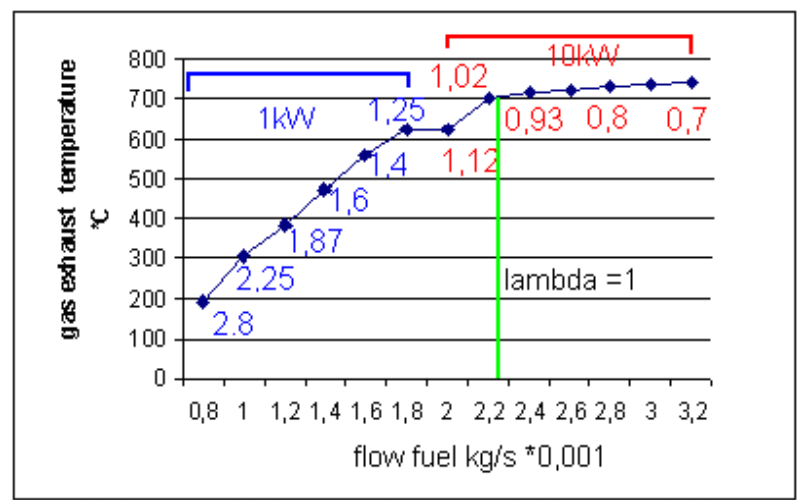

Fig. 7. The gas exhaust temperature as a function of the fuel flow for the turbine loads of 1 and $10 \mathrm{~kW}$.

Figure 8 presents simulation in a case of lean combustion using the same parameters as in Fig. 7.

As the fuel flow increases to $4.8 \mathrm{~g} / \mathrm{s}$, the exhaust temperature linearly raises. Further the load is increased to $28 \mathrm{~kW}$ and the temperature in the area of $4.8-5 \mathrm{~g} / \mathrm{s}$ is at a near constant level. It then rises again linearly to reach $980{ }^{\circ} \mathrm{C}$ at a stoichiometric mixture with a $\mathrm{CO}_{2}$ to oxygen ratio of 70:24. 


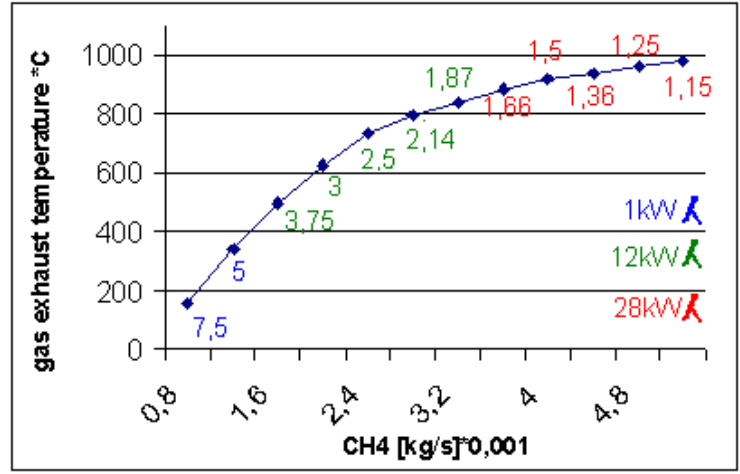

Fig. 8. Simulation in a case of lean combustion using more fuel.

Figure 9 shows a family of characteristics of changes in the mixture flow in which the ratio of the amount of fuel to oxygen and $\mathrm{CO}_{2}$ does not change; this was determined as the ratio of the amount of oxygen and $\mathrm{CO}_{2}$ to the amount of fuel $\left(\mathrm{CO}_{2}+\mathrm{O}_{2}\right) / \mathrm{F}$. Four cases were tested for ratio $\left(\mathrm{CO}_{2}+\mathrm{O}_{2}\right) / \mathrm{F}=16,28,36,45$.

The power generated increases linearly from 1 to $30 \mathrm{~kW}$. It should also be added that changes in the ratio $\left(\mathrm{CO}_{2}+\right.$ $\left.\mathrm{O}_{2}\right) / \mathrm{F}$ cause changes in $\lambda$ of the mixture. For $\left(\mathrm{CO}_{2}+\right.$ $\left.\mathrm{O}_{2}\right) / \mathrm{F}=16$, the turbine runs on a very rich mixture $(\lambda=$ 0.32 ) over the entire range.

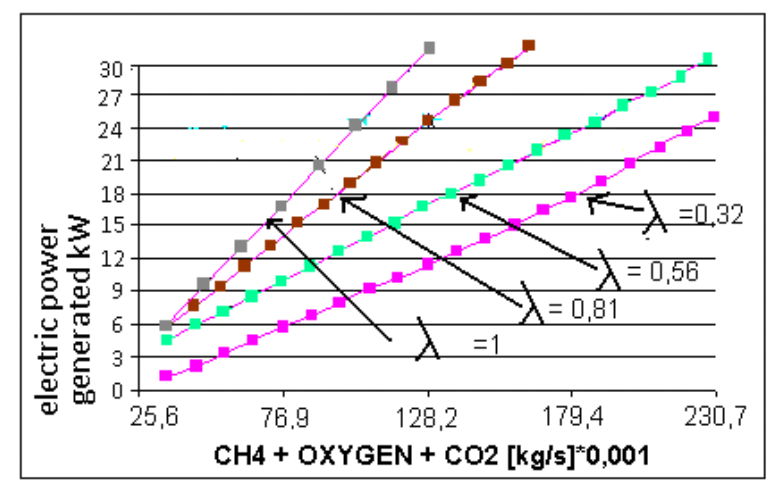

Fig. 9. Comparison of turbine power generated by the turbine for 4 different mixtures from rich to stoichiometric.

Figure 10 presents a similar situation to Fig. 9 showing in addition thermal power that can be used. One can see the heat transferred to the secondary circuit and the generated electric power as a function of the amount of the mixture for the ratio $\left(\mathrm{CO}_{2}+\mathrm{O}_{2}\right) / \mathrm{F}=36$, i.e. per 1 gram $\mathrm{CH}_{4}$ there is $36 \mathrm{~g}$ of $\mathrm{CO}_{2}+\mathrm{O}_{2}$ (in mass ratio $10 \%$ $\mathrm{O}_{2}$ and $\left.90 \% \mathrm{CO}_{2}\right)$ in the range from 40 to $250 \mathrm{~g} / \mathrm{s}(\lambda=$ $1)$. Increasing the oxygen content to $10 \%$ results in the temperature increase in the combustion chamber and thus the power generated by the turbine, the heat measured has a constant proportion to the power generated, it is 3.6 times higher. The turbine achieves its nominal power at a mixture flow of $190 \mathrm{~g} / \mathrm{s}$ and it produces $110 \mathrm{~kW}$ of heat.

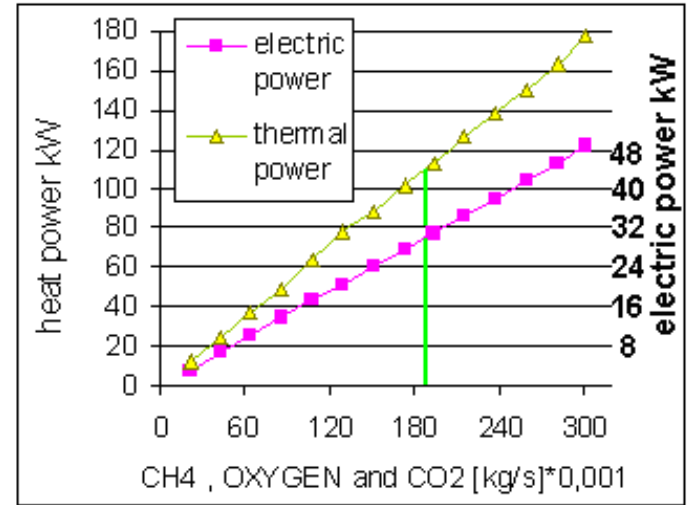

Fig. 10. Available power generated as a function of increasing the amount of mixture in ratio $\left(\mathrm{CO}_{2}+\mathrm{O}_{2}\right) / \mathrm{F}=36$

Figure 11 presents the exhaust gas temperature behind the turbine and oxygen demand as a function of the percentage of oxygen in the mixture for a turbine load of $30 \mathrm{~kW}$. The composition is controlled so that the combustion is stoichiometric and the generated electric power is at the level of $30 \mathrm{~kW}$, the oxy composition changes in the range of 5 to $16 \%$ of oxygen resulting in the inlet gas flow changes.

As the oxygen concentration increases, the mass demand decreases, the smaller amount of $\mathrm{CO}_{2}$ causes a gradual increase in the gas temperature at the turbine outlet to the level of about $930{ }^{\circ} \mathrm{C}$ for a $16 \%$ of oxygen and the input gas flow does not exceed $70 \mathrm{~g} / \mathrm{s}$.

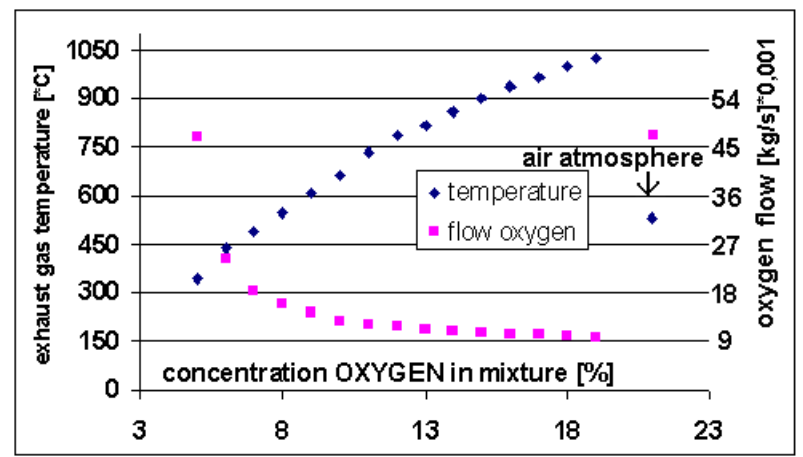

Fig. 11. Exhaust gas temperature behind the turbine and oxygen demand as a function of the percentage of oxygen in the gas mixture for a load of $30 \mathrm{~kW}$.

\section{Conclusions}

Providing the turbine with a stoichiometric mixture is essential to ensure that the flue gases are highly clean and can be processed with little energy. Such parameters are for the ratio $\left(\mathrm{CO}_{2}+\mathrm{O}_{2}\right) / \mathrm{F}$ in the range of $35-55$.

Depending on the oxygen content in the oxidant, adjustable parameters such as : amount of injected fuel, the amount of oxygen supplied and the amount of $\mathrm{CO}_{2}$ returned make it possible to smoothly change $\left(\mathrm{CO}_{2}+\right.$ $\left.\mathrm{O}_{2}\right) / \mathrm{F}$ ratio. 


\section{References}

1.Czakiert T., W. Nowak. Polish National Strategic Program on Oxy-Fuel Combustion - 5 Years of Studies and Investigations. Proc. of the 22nd International Conference on Fluidized Bed Conversion, June 14-17, Turku, Finland, 301-313, (2015).

2.Dennis R. ARPA-E Workshop, NETL, (2017).

3.Ricardo Llorente Manso. Master's Thesis. Norwegian University of Science and Technology, (2013).

4. Snarheim S.. PhD Thesis "Control issues in oxy-fuel combustion", The Norwegian University of Science and Technology, (2009).

5. Ditaranto M., Inge Saanum, Petter E. Røkke, Janczewski J., Testing of a gas turbine oxy-fuel burner. 5th Meeting of the IEAGHG InternationalOxyfuel Combustion Research NetworkWuhan, Hubei, China26 29 October,(2015).

The authors would like to thank King AbdulazizCity forScience and Technology (KACST) of Saudi Arabia for their support. 